\title{
The Effects of Posture on Neck Flexion Angle While Using a Smartphone according to Duration
}

\author{
Sang-Yong Lee, PhD, PT • Dae-Hee Lee, PhD, PT - Seul-Ki Han, PhD, PT ${ }^{\dagger}$ \\ Department of Physical Therapy, U1 University
}

Received: May 9, 2016 / Revised: May 18, 2016 / Accepted: July 3, 2016

(C) 2016 J Korean Soc Phys Med

\section{| Abstract |}

PURPOSE: The purpose of this study was to examine changes in the neck flexion angle according to posture while using a smartphone and the duration of smartphone usage.

METHODS: The subjects in this study were 16 healthy young students in their $20 \mathrm{~s}$. The subjects wore a cervical range of motion instrument. They were instructed to use a smartphone while standing, sitting on a chair, and sitting on the floor. In all postures, they could use the smartphone and use their arms freely while keeping their back connected to the wall or the back of the chair. When sitting on the floor, they assumed a cross-legged position. The neck flexion angle was measured at zero, three, six, and nine minutes for each posture.

RESULTS: Neck flexion is affected by the posture while using a smartphone $(\mathrm{p}<.05)$. Neck flexion in the standing position is larger than that in the sitting on the floor position. Neck flexion was affected by smartphone usage duration $(\mathrm{p}<.05)$. In general, as usage time increases, the neck flexion angle increases as well.

CONCLUSION: This study suggests that using

†Corresponding Author : lovewisd@ul.ac.kr

This is an Open Access article distributed under the terms of the Creative Commons Attribution Non-Commercial License (http://creativecommons.org/licenses/by-nc/3.0) which permits unrestricted non-commercial use, distribution, and reproduction in any medium, provided the original work is properly cited. smartphone in the standing position and for a short period of time is a method to reduce the neck flexion angle.

Key Words: CROM, Neck flexion angle, Posture, Smartphone

\section{Introduction}

In modern society, smartphone penetration and the number of smartphone users are increasing rapidly (Park et al., 2015). Modern people use a smartphone in most areas of their lives, including occupational and leisure activities, which means their duration of smartphone usage is also increasing (Lee et al., 2015). Most diseases of the musculoskeletal system are caused by repeated use of the system, which results in damage to the muscular fibers and muscle tone (Um, 2013). Therefore, repeated and prolonged use of smartphones will have negative impacts on the human body. Yoon et al. (2015) noted that walking using a smartphone had a negative effect on the lumbar (Yoon et al., 2015), and Straker et al. (2008) reported that the muscular activity of the muscles around the shoulders increased due to smartphone usage (Straker et al., 2008). In addition, Kim et al. (2015) stated that when using a smartphone, individuals with minor neck pain tend to bend 
their neck slightly more than individuals without neck pain. Regarding these problems with the musculoskeletal system resulting from the use of a smartphone (Kim et al., 2015), Young et al. (2012) noted that these were related to the location of the smartphone (Young et al., 2012), and Lee et al. (2006) argued that neck pain in a sitting posture is associated with the fact that an object at which an individual intends to look is located around the knee (Lee et al., 2006).

Thus, studies on the effects of smartphone use on the skeletal and muscular system have been reported, although studies on smartphone usage posture and its effect on the changes of the neck flexion angle over time are insufficient. In this regard, the purpose of this study was to examine changes in the neck flexion angle according to posture while using a smartphone and the duration of smartphone usage.

\section{Methods}

The subjects in this study were 16 healthy young students in their 20s attending U1 University in Chungbuk, South Korea. Subjects were included if they had no musculoskeletal or neurological disorders affecting the upper or lower extremities, lesions, or history of surgery of the spine or upper extremities. The mean age, height, and weight of the subjects were $20.00 \pm .37$ years, 168.09 $\pm 8.83 \mathrm{~cm}$, and $64.79 \pm 12.52 \mathrm{~kg}$, respectively. Ethical approval for the study was granted by the Institutional Review Board of U1 University. All subjects were fully informed of the objectives and methods of the study beforehand and gave informed consent to participate in the experiments.

The subjects wore a cervical range of motion (CROM, Performance Attainment Associates, US) instrument. They were instructed to use a smartphone while standing, sitting on a chair, and sitting on the floor. In all postures, they could use the smartphone and use their arms freely while keeping their back connected to the wall or the back of the chair. When sitting on the floor, they assumed a cross-legged position (Fig. 1). Posture, procedure and method are selected randomly. The neck flexion angle was measured at zero, three, six and nine minutes for each posture. All participants for this study used the Galaxy Note3 (SM-N900S, Samsung Electronics Co., LTD, Seoul, Korea) smartphone to surf the internet freely. Subjects were free to the web surfing. The two-way ANOVA was performed to examine changes in the neck flexion angle according to posture and duration. The Bonferroni post hoc test was also performed. In the present study, the date was statistically processed using SPSS/PC Ver. 12.0, and the significance level $a$ was set to .05 .

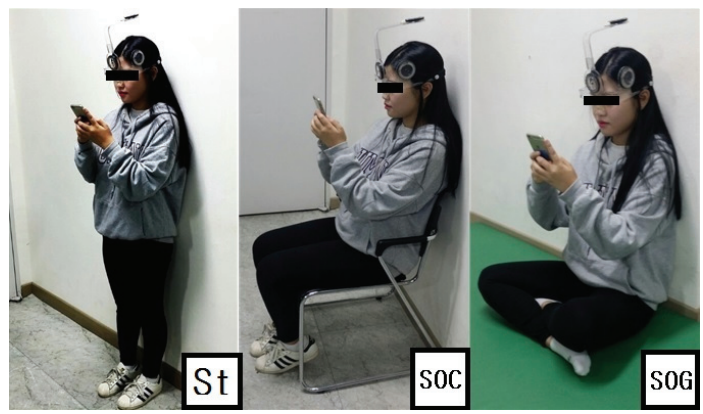

Fig. 1. The posture of St, SOC and SOG

\section{Results}

Neck flexion angle while using smartphone was affected by both posture and usage time $(\mathrm{p}<.05)$ and there was no interaction between posture and usage time. The result of post-analysis showed that standing - position and the sitting in a chair position comprised one group, and sitting in a chair position and sitting on the floor position comprised an another group. The flexion angle for the group including the standing position was larger than that of the group including the sitting position on the floor position. As 
The Effects of Posture on Neck Flexion Angle While Using a Smartphone according to Duration | 37

Table 1. The Effects of Posture on Neck Flexion Angle While Using a Smartphone

(unit: degree)

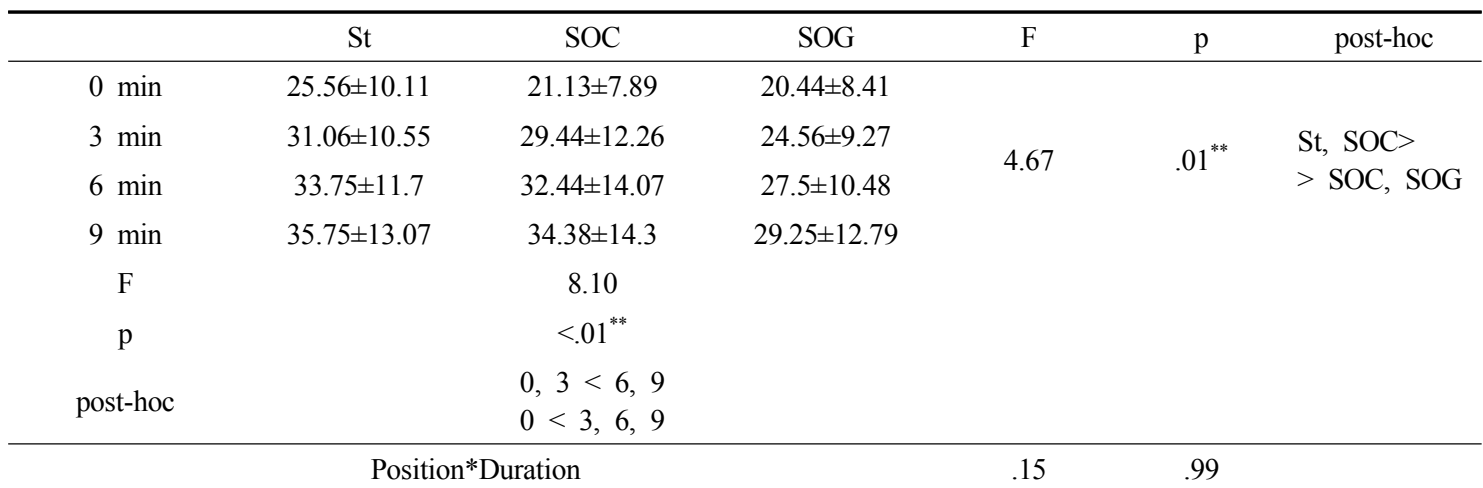

${ }^{*} \mathrm{p}<.05,{ }^{*} \mathrm{p}<.01 ;$ St: Stand; SOC: Sit on Chair; SOG: Sit on Ground

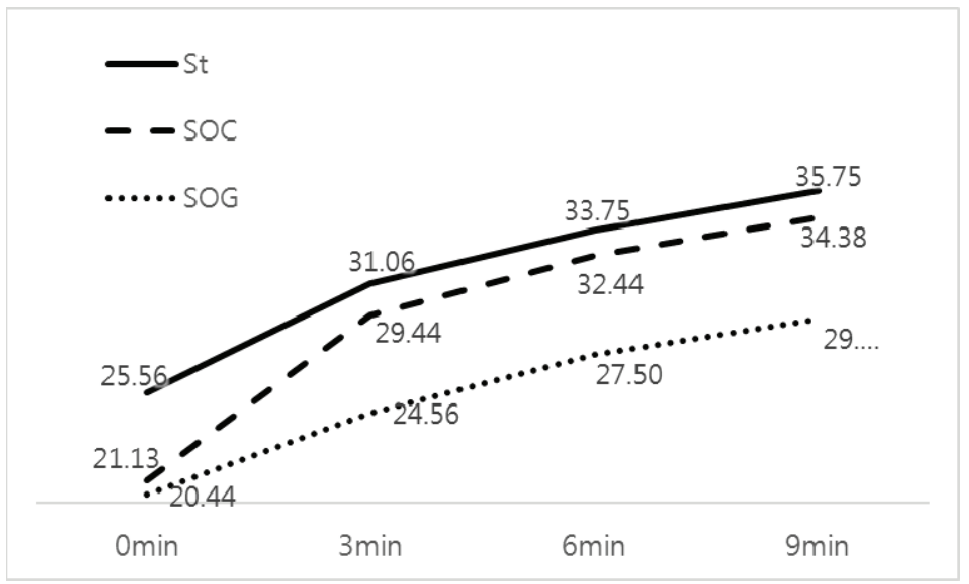

Fig. 2. The Effects of Posture on Neck Flexion Angle While Using a Smartphone (unit: degree)

smartphone usage time became longer, the neck flexion angle increased (table1) (Fig. 2).

\section{Discussion}

The subjects in this study were 16 healthy young students in their 20s. They were instructed to use a smartphone while standing, sitting on a chair, and sitting on the floor Neck flexion angle was increased significantly over time in all postures. At three, six and nine minutes for each posture.

In this study, the maximum measurement time was 9 mins, because the minimum smartphone usage time at which users started to complain about pain or fatigue was 10 mins. Kim and Kim (2015) reported that a longer duration of smartphone usage caused a higher degree of pain. In line with this result, the present study shows that a longer duration of smartphone usage led to a higher neck flexion angle for each of the three postures. This result was obtained even though the participants were required to lean their backs against the wall. In daily life when 
there is no requirement to lean their backs against the wall, it is expected that the overall posture including neck posture will be bent more. This kind of excessive neck flexion can cause deformation of the normal neck bone into a $\mathrm{C}$ shape (Lee, 2013) and fatigue on the neck and muscle around shoulder (Ko et al., 2013; Strake, 2008).

Kim (2015) reported that while using a smartphone, individuals with minor neck pain bent their neck slightly more than those without neck pain, although the causal relationship could not be identified (Kim, 2015). In this regard, Lee and Seo (2014) noted that a higher degree of smartphone addition may lead to a reduction in the ability to recognize neck posture (Lee and Seo, 2014). These studies suggest that the use of a smartphone can impair the sensory ability to recognize neck posture, thereby becoming a factor that causes pain by bending the neck at a higher angle. In addition, squatting postures, especially when bending the neck, cause psychologically negative results. Carney et al. (2010) reported that during a straight posture, the secretion of testosterone went up by $20 \%$ and the secretion of cortisol went down by $25 \%$, whereas during a squatting posture, the secretion of testosterone went down $10 \%$ and the secretion of cortisol went up 15\% (Carney et al., 2010). In other words, stress can be generated more easily in a squatting posture. This shows that bending the neck while using a smartphone has a negative effect. In relation to this, some researchers recommend assuming postures where the neck can be straighter while using a smartphone (Kim 2015; Kim and Kim 2015). In the present study, when the subjects used a smartphone, they bent their neck at a higher degree while standing compared to sitting on thefloor. Standing position while using a smartphone required much more bending of the neck than the sitting on the floor position from the beginning of the use of a smartphone; therefore, smartphone use in standing position needs to restrained.

There were several limitations to this study. First, the subjects were restricted to young students in their 20 s, which makes it difficult to normalize the results, Second, there was a small study group number.

\section{Conclusion}

The purpose of this study was to examine changes in the neck flexion angle according to posture while using a smartphone and the duration of smartphone usage. This study result is as follows.

1. Neck flexion is affected by the posture while using a smartphone $(\mathrm{p}<.05)$. Neck flexion in the standing position is larger than that in the sitting on thefloor position.

2. Neck flexion was affected by smartphone usage duration $(\mathrm{p}<.05)$. In general, as usage time increases, the neck flexion angle increases as well.

In conclusion, neck flexion, which causes problems including pain in the skeletal and muscular system, is affected by posture and usage time. This study suggests that using smartphone in the standing position and for a short period of time is a method to reduce the neck flexion angle.

\section{References}

Carney DR, Cuddy AJ, Yap AJ. Power posing: brief nonverbal displays affect neuroendocrine levels and risk tolerance. Psychol Sci. 2010;21(10):1363-8.

Kim HJ, Kim JS. The relationship between smartphone use and subjective musculoskeletal symptoms and university students. J Phys Ther Sci. 2015;27(3): 575-9.

Kim MS. Influence of neck pain on cervical movement in the sagittal plane during smartphone use. J Phys Ther 
Sci. 2015;27(1):15-7.

Ko K, Kim HS, Woo JH. The study of muscle fatigue and risks of musculoskeletal system disorders from text inputting on a smartphone. J Ergon Soc Korea. 2013;32(3):273-8.

Lee H, Nicholson LL, Adams RD, et al. Development and psychometric testing of Korean language versions of 4 neck pain and disability questionnaires. Spine. 2006;31(6):1841-5.

Lee J, Seo K. The comparison of cervical repositioning errors according to smartphone addiction grades. J Phys Ther Sci. 2014;26(4):595-8.

Lee M, Hong Y, Lee S, et al. The effects of smartphone use on upper extremity muscle activity and pain threshold. J Phys Ther. 2015;27(6):1743-5.

Lee YS. A study on the effect of mobile phone use addiction on teenage health: Focused on neck pain. Seoul, Gwangwoon University, Master's Degree. 2013.
Park JW, Kim MS, Bae HS, et al. The reliability and validity of hip range of motion measurement using a smart phone operative patient. J Korean Soc Phys Med. 2015;10(2):1-7.

Straker LM, Coleman J, Skoss R, et al. A comparison of posture and muscle activity during tablet computer, desktop computer and paper use by young children. Ergonomics. 2008;51(4):540-55.

Um SH. An empirical study on relationship between physical symptoms and smartphone usage. Master's Degree. Inha University. 2013.

Yoon JO, Kang MH, Kim JS. The effects of gait with use of smartphone on repositioning error and curvature of the lumbar spine. J Phys Ther Sci. 2015;27(8): 2507-8.

Young JG, Trudeau M, Odell D, et al. Touch-screen tablet user configurations and case-supported tilt affect head and neck flexion angles. Work. 2012;41(1):81-91. 